\title{
The Comparison of Religious Orientation, Psychological Well-Being and Forgiveness in Teachers and Clergymen
}

\author{
Ahmad Usefynezhad', Hossein Salimi Bajestani' ${ }^{2}$, Hossein Jena Abadi ${ }^{3}$, \\ Mojtaba Salmabadi \\ ${ }^{1}$ Faculty of Psychology and Educational Science, Allameh Tabataba'i University, \\ Tehran, Iran \\ ${ }^{2}$ Department of Counseling, Faculty of Psychology and Education, Allameh Tabataba'i University, \\ Tehran, Iran \\ ${ }^{3}$ Department of Education, University of Sistan and Baluchestan, \\ Zahedan, Iran \\ Email: A usefy@yahoo.com
}

Received 20 January 2015; accepted 26 March 2015; published 22 July 2015

Copyright (C) 2015 by authors and Scientific Research Publishing Inc.

This work is licensed under the Creative Commons Attribution International License (CC BY). http://creativecommons.org/licenses/by/4.0/

(c) (7) Open Access

\begin{abstract}
The present study tries to compare religious orientation, psychological well-being and forgiveness in teachers and clergymen. The statistical population includes all teachers of district 2, Qazvin Education Organization and all clergymen in Qazvin Seminary (Hawzeh Elmeyyeh) in the academic year 2013-2014. Among them, 260 individuals (150 teachers and 150 clergymen) were selected by random sampling and completed the psychological well-being questionnaire, forgiveness questionnaire and religious orientation questionnaire. The results show that there is no significant difference between two groups in the psychological well-being, but there are significant differences in forgiveness and religious orientation so that in the forgiveness variable, the clergymen have higher mean than teachers and in religious orientation variable, teachers have higher mean than clergymen. Also, there are significant differences between forgiveness and psychological well-being, forgiveness and religious orientation, and psychological well-being and religious orientation in the two groups so that the rate of these relationships in teachers is significantly higher than that of clergymen. The job status (teacher or clergy) has the role of mediator. Evaluation and recognition of psychological health and well-being and the relationship of these psychological structures with forgiveness and religious orientation can present worthwhile recommendations in the field of providing psychological health for individuals of the society that requires more consideration in the field of clinical researches.
\end{abstract}




\section{Keywords}

\section{Positive Psychology, Psychological Well-Being, Forgiveness, Religious Orientation}

\section{Introduction}

In the twenty-first century, a group of psychologists have noticed this subject that human being should spend his intellectual energy in the positive aspects of the experience; so, one of the things that has attracted much attention in recent decades is Positive psychology. Today, a new perspective on health-related sciences in general and in psychology in particular is emerging and developing that aims to focus on well-being health and to explain the nature of psychological well-being (Bahadori Khosroshahiand Hashemi Nosratabad, 2011).

Psychological well-being is involved in the psychology of life quality that is defined as individuals' understanding of life in the realm of emotional behavior, psychological functioning and aspects of mental health and consists of two parts. The first part of it includes cognitive judgments about how people's lives are in progress and the second part is the level of pleasant experiences (Bahadori Khosroshahi and Hashemi Nosratabad, 2011). Some scholars conceptualize psychological well-being in standpoint of the components or particular processes as emotional processes. Also, some emphasize the physical processes and point out that there is a relationship between high physical health and the high quality of life. Some emphasize on the role of the spiritual processes such as the ending overall goal in life that leads to the optimal performance in describing psychological wellbeing. Also some others refer to the individual and social processes such as enjoying a positive attention toward self and self-dominant andsignificant associations with others (Shekari et al., 2007). Based on Ryff model, psychological well-being consists of six factors: self-acceptance, positive relationships with others, autonomy, purpose in life, personal growth and dominating on the environment; this model has been widely addressed in the world (Maddahi et al., 2011).

Koenig (2007) has shown that mental and physical health of people has a positive relationship with their spiritual life and people who have strong religious beliefs, have better adjustment with life situations. Based on previous research, that a special attention is given to the role of religion in mental health, the religion can be a unifying principle and has a great force for good mental health and is helpful (Maddahi et al., 2011).

The need of human to religion has a long life as the life of history; because from the very beginning, the human felt the existence of a strong and powerful supporter. The issue of religion has been discussed by pioneer scholars such as James, Freud, Jung and the others, and then some thinkers such as all port have explained about religion (Ryff et al., 2004). From the perspective of Allport (1996), religious orientation is as "internal" and "outer". In internal religious orientation, the faith is considered as an excellent value per se and also as a universal commitment not as a tool to achieve the objectives; But in outer religious orientation, religion is used as an extrinsic fact and a tool to meet the individual needs such as position and security; in the other words, religiosity is for social status and security, and those who have such a religious orientation use the religion as a means to meet their needs (Madahi et al., 2011). Also Allport (1966) knows the internal religious orientation a religion that the person wants it internally, lives with it and gives meaning to all his life by it; he knows the outer religious orientation a religion that the person wants for comfort, welfare, status, authority and position and social support.

In general, according to several studies, one of the factors that will help people in many situations to tolerate difficulties is religion. Religion has a negative relationship with disorders such as anxiety and depression (Wink, Dillon \& Larson, 2005). Desrosiers and Miller (2007) in a research on the young girls showed that who had strong religious beliefs, were powerful in confronting with mental, personal and educational stresses and their diseases were less likely developed, and indeed they had higher mental health; also, Ai et al. (2007) studied the patients with heart disease that the results of their study showed that patients who had strong religious beliefs and in their daily life used positive contrasting ways such as forgiveness, the search for spiritual relationship with God, friendship with religious people and receiving social and spiritual support and hope, had a faster recovery and higher mental health and lower depression and anxiety. Research also shows that among coping ways in the elders, the religion plays a major role; because religion has a positive value in filling the gap in life, supporting the elders, dealing with stress, appropriate adjustment for giving direction and meaning to life and 
death (Bolhori, NoriQasemabadi, \& RamezaniFranny, 1999).

A positive psychology component that is associated with psychological well-being is forgiveness. MacCullough, Pargament and Thoresen (2003) stated that "forgiveness" was to give direction to motivations. They have defined forgiveness as giving positive direction to negative incentives that are associated with peaceful and positive motivations toward the sinned person. Maclachan (2012) showed that forgiveness had an important role in promoting compassion, mercy and kindness. On the other hand, some people know forgiveness as having the nature of opposites, that is, both rein forces the behavior of the offender and causes personal growth. For this reason, although, mental health interventions are effective to promote forgiveness (Worthington et al., 2005), but some researches do not support the effects of effectiveness as coupling (marital) interventions (Teresa et al., 2003).

Tse and Yip (2009) showed that forgiveness had a positive and significant relationship with psychological well-being and personal compatibility. On the other hand, in a research by Khosravi et al. (2011), the findings showed that there was a significant relationship between the styles of attachment and marital conflict with forgiveness, so that couples who had more secure the attachment styles, the rate of marital conflict was lower and the rate of forgiveness was higher. In addition, some other researches show that having inclination to forgiveness towards others is associated with reduction of anger (Lawler-Row, Karremans, \& Scott, 2008), rising hopes (ZahidBabolan et al., 2011), increasing and improving social support (Lawler-Row \& Piferi, 2006), and psychological well-being (Brown, 2003). In contrast, the lack of inclination to forgiveness towards others is related with reduced coping abilities (Maltby et al., 2004) and increased depression and anxiety (Maltby, Macaskill and Day, 2001).

The results of some other studies have emphasized the impact of forgiveness. For example, a significant relationship was observed between forgiveness and mental health in couples as well as between the level of forgiveness in the principal family, the nuclear family and marital satisfaction (Saif, Bahari and Khosravi, 2006). Also, in a study that was done on 200 couples, a significant relationship was observed between the level of forgiveness and marital satisfaction, duration of marriage and the level of education in couples (Hosseini, 2003).

Therefore, there is a significant relationship between the variables of religious orientation, psychological wellbeing and forgiveness; and in recent years, researchers have been specifically addressed the issue of religion. So, it is necessary to investigate if the religion as an internal and external source has a role in psychological wellbeing and mental health in both teachers and clergymen not; and if the result is positive, this role is considered as an important component. Especially, considering the type of religion (internal or external), a positive role in the relationship between religion, psychological well-being and forgiveness can be defined. Since a research to compare these variables in the studied population has not been conducted and a gap is felt in this area and the aim of the present study is to fill a part of the research gap, so the researcher is going to study the relationship between religious orientation, psychological well-being and forgiveness in both teachers and clergymen and to compare them.

\subsection{Research Method}

The research method in this study is a comparative one. The studied population in this research includes all the teachers working in Qazvin Education Organization region 2 and all Clergymen in Qazvin Seminary (Howzeh Elmeyyeh) in academic year 2012-2013. The study sample consists of 150 teachers and 150 clergymen in the city of Qazvin that were randomly selected from the population.

\subsection{Research Tools}

Psychological well-being scale: This scale was designed in 1989 by Ryff. This scale has six subscales selfacceptance, positive relations with others, autonomy, purpose in life, personal growth and dominating on the environment. In this study, the researcher has used the 18-item form that each item is scored as 1-2-3-4-5-6. The higher score indicates better mental well-being. The coefficient amplitude for internal reliability has been reported between 0.65 and 0.70 for different dimensions of Ryff scale (Lindforce, Brentson and Landberg, 2006). The validity and reliability of the questionnaire in the Iranian sample has been confirmed (Baiani and Kocheki, 2008). In the present study, the reliability was obtained 0.87 by Cronbach's alpha method.

Ray forgiveness scale: This scale was prepared by Ray (2001) that includes the two scales of lack of negative sense and having positive sense. The original scale has 16 items; the options are as "Yes", "sometimes" and "No" 
that are scored as "0-1-2"; the items 1-4-7-9-11-12-13 are inversely scored; in other words, the score of 2 is to select "Yes" and the score of zero is to select "No". The higher score in this scale indicates more forgiveness toward wrongdoer (Rye et al., 2001). Ray compares this criterion with the measure of Enright. The obtained correlation by matching method was relatively high (Ray et al., 2001). Also, the Cronbach's alpha of this tool obtained as 0.96 in the research by Zandipour and Yadgari (2007). In the present study, the reliability was obtained equal to .079 by Cronbach's alpha method.

Allport religious orientation scale: All port and Russ prepared this scale to measure internal and external religious orientation in 1950. In the initial studies that were conducted on this basis, it was observed that the correlation between the outer and inner orientations is 0.21 (Hosseininasab, 2009). This test has been translated and standardized in 2008. Its internal consistency was obtained equal to 0.71 using Cronbach's alpha; and its reliability was also obtained as 0.74 through test-retest method (Mokhtari, 1990). In this 21-item scale, the items 1 to 12 measure the outer religious orientation and items 13 to 21measure the internal religious orientation and are scored based on Likertscoring. In the present study, reliability was obtained equal to 0.82 by Cronbach's alpha method.

\subsection{Research Procedure}

Data collection was performed using a standard questionnaire. And finally the data extracted from the questionnaire and applied into SPSS software and analysis was performed. And for analyzing data, descriptive statistics methods (mean, standard deviation, the highest and lowest scores) and inferential statistical test, analysis of variance MANOVA were used to test hypothesis.

\section{Findings}

Descriptive analysis of respondents' demographic data showed that this population included $53.3 \%$ male and 46.7\% females among whom $18.3 \%$ were single and $81.7 \%$ were married. $25.3 \%$ held Associate's Degree, 57.3\% Bachelor's Degree, and 17.4\% Master's Degree (Table 1).

According to the Table 2, we can see that there is no significant difference between the variable of well-being in two groups, but for variables of forgiveness and orientation there are significant differences in two groups of teachers and clergymen so that in forgiveness variable the mean of clergymen is significantly higher than that of teachers and in orientation variable the mean of teachers is significantly higher than that of clergymen.

According to the Table 3, we can observe that the correlation between the two variables of forgiveness and psychological well-being in both groups of clergymen and teachers and in general is significant so that this sig-

Table 1. The mean, standard deviation and alpha related to research variables.

\begin{tabular}{|c|c|c|c|c|}
\hline & Indicator & General & Teachers & Clergymen \\
\hline \multirow{4}{*}{ Forgiveness } & Minimum & 8 & 14 & 2 \\
\hline & Maximum & 21.7 & 16. 7 & 26.7 \\
\hline & Average & 16.86 & 15.26 & 18.51 \\
\hline & Standard deviation & 4.13 & 5.37 & 3.65 \\
\hline \multirow{4}{*}{ Well-being } & Minimum & 8.7 & 8 & 9.3 \\
\hline & Maximum & 3.7 & 3.3 & 4 \\
\hline & Average & 64.36 & 65.37 & 63.4 \\
\hline & Standard deviation & 9.01 & 8.87 & 9.39 \\
\hline \multirow{4}{*}{ Orientation } & Minimum & 4.3 & 3.3 & 5.3 \\
\hline & Maximum & 0.3 & 0.7 & 0 \\
\hline & Average & 60.89 & 61.66 & 60.11 \\
\hline & Standard deviation & 6.21 & 6.15 & 6.47 \\
\hline
\end{tabular}


Table 2. Independent t-test analysis variables of teachers and clergymen.

\begin{tabular}{|c|c|c|c|c|c|c|c|}
\hline & Job & Number & Mean & $\begin{array}{l}\text { Standard } \\
\text { deviation }\end{array}$ & $\mathrm{t}$ & $\begin{array}{l}\text { Degrees of } \\
\text { freedom }\end{array}$ & $\begin{array}{c}\text { Significan } \\
\text { level }\end{array}$ \\
\hline \multirow{2}{*}{ Forgiveness } & Teachers & 150 & 15. 26 & 5. 37 & \multirow{2}{*}{-6.13} & \multirow{2}{*}{298} & \multirow{2}{*}{0.000} \\
\hline & Clergymen & 150 & 18. 51 & 3. 65 & & & \\
\hline \multirow{2}{*}{ Well-being } & Teachers & 150 & 65. 37 & 8. 87 & \multirow{2}{*}{1.87} & \multirow{2}{*}{298} & \multirow{2}{*}{0.062} \\
\hline & Clergymen & 150 & 63.4 & 9. 39 & & & \\
\hline \multirow[b]{2}{*}{ Orientation } & Teacher & 150 & 61.66 & 6. 15 & \multirow[b]{2}{*}{2.13} & \multirow[b]{2}{*}{298} & \multirow{2}{*}{0.034} \\
\hline & Clergymen & 150 & 60.11 & 6. 47 & & & \\
\hline
\end{tabular}

Table 3. The results of Pearson correlation coefficient for forgiveness and psychological well-being and comparison of them in teachers and clergymen.

\begin{tabular}{|c|c|c|c|c|c|c|}
\hline & & \multicolumn{3}{|c|}{ Psychological well-being } & \multirow{2}{*}{ Z-test } & \multirow{2}{*}{ Significance leve } \\
\hline & & General & Teachers & Clergymen & & \\
\hline \multirow{4}{*}{ Forgiveness } & Correlation & 0.347 & 0.571 & 0.207 & \multirow{3}{*}{14.56} & \multirow{3}{*}{0.000} \\
\hline & Significant level & 0.000 & 0.000 & 0.011 & & \\
\hline & Number & 300 & 150 & 150 & & \\
\hline & & \multicolumn{2}{|c|}{ Determination coefficient } & \multicolumn{2}{|c|}{$\mathrm{F}$} & $\mathrm{p}$ \\
\hline \multicolumn{2}{|c|}{ General } & \multicolumn{2}{|c|}{0.121} & \multicolumn{2}{|c|}{40.83} & 0.000 \\
\hline \multicolumn{2}{|c|}{ Teachers } & \multicolumn{2}{|c|}{0.326} & \multicolumn{2}{|c|}{71.69} & 0.000 \\
\hline \multicolumn{2}{|c|}{ Clergymen } & \multicolumn{2}{|c|}{0.043} & \multicolumn{2}{|c|}{6.61} & 0.011 \\
\hline
\end{tabular}

nificance is 0.207 in clergymen and 0.571 in teachers and 0.347 in general. By investigating the difference between the level of correlation in both teacher and clergyman groups, we can see that the value of the test statistic equals to 14.56 that reports the significance of 0.000 which is lower than 0.05 that indicates this relationship in teacher group is significantly higher than the clergyman group. Also in the Table 3, the rate of determination coefficient is 0.121 in general which makes the regression test significant (the significance level is less than 0.05). This significance is 0.326 for teachers and 0.043 for clergymen that shows, for teachers, $32.6 \%$ of variables are predictable by other variables, while in clergymen this value is only $4.3 \%$.

According to the Table 4, we can observe that the correlation between the two variables of forgiveness and religious orientation in both groups of clergymen and teachers and in general is significant so that this significance is 0.432 in clergymen and 0.646 in teachers and 0.468 in general, that by investigating the difference between the level of correlation in both teacher and clergyman groups, we can see that the value of the test statistic equals to 15.71 that reports the significance of 0.000 which is lower than 0.05 that indicates this relationship in teacher group is significantly higher than the clergyman group. Also in the Table 4, the rate of determination coefficient is 0.219 in general which makes the regression test significant (the significance level is less than 0.05). This significance is 0.417 for teachers and 0.187 for clergymen that shows, for teachers, $41.7 \%$ of variables are predictable by other variables, while in clergymen this value is only $18.7 \%$.

According to the Table 5, we can observe that the correlation between the two variables of Psychological well-being and religious orientation in both groups of clergymen and teachers and in general is significant so that this significance is 0.358 in clergymen and 0.517 in teachers and 0.411 in general, that by investigating the difference between the level of correlation in both teacher and clergyman groups, we can see that the value of the test statistic equals to 10.31 that reports the significance of 0.001 which is lower than 0.05 that indicates this relationship in teacher group is significantly higher than the clergyman group. Also in the Table 5, the rate of determination coefficient is 0.169 in general which makes the regression test significant (the significance level is less than 0.05 ). This significance is 0.267 for teachers and 0.128 for clergymen that shows, for teachers, $26.7 \%$ of variables are predictable by other variables, while in clergymen this value is only $12.3 \%$. 
Table 4. The results of Pearson correlation coefficient for forgiveness and religious orientation and comparison of them in teachers and clergymen.

\begin{tabular}{|c|c|c|c|c|c|c|}
\hline & & \multicolumn{3}{|c|}{ Religious orientation } & \multirow{2}{*}{ Z-test } & \multirow{2}{*}{ Significance leve } \\
\hline & & General & Teachers & Clergymen & & \\
\hline \multirow{3}{*}{ Forgiveness } & Correlation & 0.468 & 0.646 & 0.432 & \multirow{3}{*}{15.71} & \multirow{3}{*}{0.000} \\
\hline & Significant level & 0.000 & 0.000 & 0.000 & & \\
\hline & \multirow[t]{2}{*}{ Number } & 300 & 150 & 150 & & \\
\hline & & \multicolumn{2}{|c|}{ Determination coefficient } & \multicolumn{2}{|c|}{$\mathrm{F}$} & $\mathrm{p}$ \\
\hline \multicolumn{2}{|c|}{ General } & \multicolumn{2}{|c|}{0.219} & \multicolumn{2}{|c|}{86.56} & 0.000 \\
\hline \multicolumn{2}{|c|}{ Teachers } & \multicolumn{2}{|c|}{0.417} & \multicolumn{2}{|c|}{106.175} & 0.000 \\
\hline \multicolumn{2}{|c|}{ Clergymen } & \multicolumn{2}{|c|}{0.187} & \multicolumn{2}{|c|}{33.95} & 0.000 \\
\hline
\end{tabular}

Table 5. The results of Pearson correlation coefficient for psychological well-being and religious orientation and comparison of them in teachers and clergymen.

\begin{tabular}{|c|c|c|c|c|c|c|}
\hline & & \multicolumn{3}{|c|}{ Religious orientation } & \multirow{2}{*}{ Z-test } & \multirow{2}{*}{ Significance level } \\
\hline & & General & Teachers & Clergymen & & \\
\hline \multirow{4}{*}{$\begin{array}{l}\text { Psychological } \\
\text { well-being }\end{array}$} & Correlation & 0.411 & 0.517 & 0.358 & & \\
\hline & Significant level & 0.000 & 0.000 & 0.000 & 10.31 & 0.001 \\
\hline & Number & 300 & 150 & 150 & & \\
\hline & \multicolumn{2}{|c|}{ Determination coefficient } & \multicolumn{2}{|c|}{$\mathrm{F}$} & \multicolumn{2}{|r|}{$\mathrm{p}$} \\
\hline General & \multicolumn{2}{|c|}{0.169} & \multicolumn{2}{|c|}{71.84} & \multicolumn{2}{|r|}{0.000} \\
\hline Teachers & \multicolumn{2}{|c|}{0.267} & \multicolumn{2}{|c|}{54.129} & \multicolumn{2}{|r|}{0.000} \\
\hline Clergymen & \multicolumn{2}{|c|}{0.128} & \multicolumn{2}{|c|}{21.72} & \multicolumn{2}{|r|}{0.000} \\
\hline
\end{tabular}

\section{Discussion and Conclusion}

According to the positive psychology growth in recent decades, and also according to the religious and spiritual activities that influence the aspects of this field, including the psychological well-being, the present study was conducted to compare religious orientation, psychological well-being and forgiveness in teachers and clergymen in Qazvin. Generally, the human well-being depends on confronting the issues of everyday life and experiences gained from these issues, which can affect the attitude, thoughts and opinions of an individual in life associations.

The results showed that there is no significant difference in psychological well-being between the two groups. But there are significant differences in the variables of forgiveness and religious orientation so that in variable of forgiveness the mean for clergymen is higher than that for teachers and in variable of religious orientation the mean for teachers is higher than that for clergymen which implies that teachers' forgiveness is less than that of clergymen, but in religious orientation the rate of this variable is higher in teachers than in clergymen; The findings of this research are consistent and congruent with the results of Maclachan (2012) and Arian et al. (2008). In explaining this finding, we can say that the forgiving behavior cannot be explained in the light of religious orientation. But forgiving behavior of clergymen can be explained with reference to different experiences, as distinct experience of the behaviors and patterns. In society, a person with a different profession than that of clergymen, for example, a teacher can have religious orientation like a clergyman; but in addition to religious orientation, the fact of being a clergyman will form a system of behaviors and experiences.

Also, in elucidation of being high the mean of forgiveness in clergymen in the population of the present study, we can mention factors such as the different spiritual life of a clergyman in a religious discourse with my own 
special indices and also deeper affectability of clergymen from ontological concepts such as the fallibility of human being and that he who ignores the error of his people, the Lord will forgive him/her. From this perspective, it is likely that the clergyman discourse is defined as an ideological set or system that enjoys the institutionalized behavior which influences the subjectivity; and even sometimes it casts a shadow on knowledge and awareness of a historical period, without they can be aware of this conscious subjectivity, a subject that can be an introduction to the future researches.

The second finding of the present study showed that in relationship between forgiveness and psychological well-being, there is no significant difference in both groups so that the rate of this relationship in teacher group is significantly higher than the clergyman group. Therefore, job status (teacher or clergy) plays the role of mediator. This finding is consistent with the results of previous researches such as Tse and Yip (2009), Brown (2003), Zahed Babolan et al. (2011), Seif et al. (2006). In explaining this finding, we can say that since both groups of the studied population are the vigorous and normal individuals, and the studied universe is a population that in which religion and religious values are of great interest and the importance of religiosity and religious behaviors such as prayer, benediction and participation in religious ceremonies and etc in various forms but similarly are placed in hands of various groups, including teachers and clergymen, it seems logical that in this term there is a difference between these two groups.

In the relationship between forgiveness and religious orientation, there is a significant difference between two groups so that the rate of this relationship is significantly higher in teacher group than in clergy group. So, job status (teacher or clergy) plays the role of mediator and this finding is consistent with the findings of the study by Nori and Kazemi (2012) that showed there is a significant correlation between the religious orientation and rate of willingness to forgive among adolescents. In explaining the above finding, it may be said that although religion and religious principles and beliefs of each individual provide recommendations on how to spend the life, but at the same time affect their attitude towards different phenomena. On this basis it may be said that the religious adherence naturally affects the individuals' behaviors and beliefs towards different phenomena; and this causes a change in the person's thoughts and beliefs and also causes the individual looks at the world positively and has forgiveness and pardon about problems. On this basis, achieving such a result is not unexpected (Golparvar \& Khaksar, 2007).

The last finding of this research revealed that in the relationship between the religious orientation and wellbeing, there is a significant difference between the two groups so that the rate of this relationship is significantly higher in teacher group than in clergy group. So, job status (teacher or clergy) plays the role of mediator. This finding implies that teachers have higher religious orientations and forgiveness than the clergymen. This finding is consistent with the findings of the previous researches including Arian et al. (2008), Bahrami et al. (2006), Desrosiers and Miller (2007) and Ai et al. (2007). In explaining the above finding, it may be said that the religious behaviors and beliefs have a positive impact on making the life meaningful. Behaviors such as trust in God, prayer, pilgrimage etc can cause the inner peace through creating hope and encouragement toward positive attitudes. Having meaning and purpose in life, the feeling of belonging to a sublime source, hopping to God's help in difficult conditions of life, the enjoyment of social and spiritual support, etc. all are of the ways by having them the religious people are less damaged when confronting disasters resulting from life pressures (Yang \& Mao, 2007); and this can lead to increase mental health and as a result, to improve psychological well-being.

Of limitations of this study, we can refer to limitations of implementation of the questionnaire and lack of cooperation of authorities in conducting research and sometimes their resistance against implementation of the study. Also, the problems and limitations related to reporting tools must not be ignored. Since, the statistical universe and the sample were teachers and clergymen in the city of Qazvinwe should be precautious in generalization of the results to the other populations. It is suggested that some studies are conducted on this subject in different groups and in both genders at local and national levels. Also it is suggested that the future researches examine the differences between the genders with the same variables of the present study.

\section{References}

Ai, A.L., Park, C.L., Huang, B., Rodgers, W., \& Tice, T.N. (2007). Psychosocial Mediation of Religious Coping Styles: A Study of Short-Term Psychological Distress Following Cardiac Surgery. Personality and Social Psychology Bulletin, 33, 867-882. http://dx.doi.org/10.1177/0146167207301008

Allport, G. W. (1996). Religious Context of Prejudice. Journal for the Scientific Study of Religion, 26, 447-457. 
Bolhori, J., NoriQasemabadi, R., \& RamezaniFarani, A. (1999). Quranic verses in the Field of Mental Health. Tehran: Tehran Psychiatric Institute, The World Health Organization Collaborating Centre for Mental Health.

Brown, R. P. (2003). Measuring Individual Differences in the Tendency to Forgive: Construct Validity and Links with Depression. Personality and Social Psychology Bulletin, 29, 759-771.

Desrosiers, A., \& Miller, L. (2007). Relational Spirituality and Depression in Adolescent Girls. Journal of Clinical Psychology, 63, 1021-1037. http://dx.doi.org/10.1002/jclp.20409

Golparvar, M. and Khaksar, S. (2007). The Role of Religiosity and Internal and Outer Religious Orientation in Distributive and Procedural Fair World Beliefs of Female Students. Proceedings of the Conference on Mental Health and Students, 3 , 101-104.

Hosseini, A. S. (2003). The Correlation of Forgiveness between Original Families and Nuclear Ones and Its Relationship with Couples' Marital Satisfactions. MSc Thesis, Tehran: University of Well-Being and Rehabilitation.

Hosseininasab, D., Hashemi, T., \& FotoohiBonab, S. (2009). The Study of the Relationship between Religious Orientation and Marital Adjustment. Psychology Research-Scientific Journal, Tabriz University of Tabriz, 4, 97-106.

Khosravi, Z., Beliad, M. R., Nahidpour, F., \& Azadi, Sh. (2011). The Investigation of the Relationship between Attachment Styles, Forgiveness and Marital Conflicts in Couples Referring to Counseling Center in the City of Karaj. Women Quarterly Journal of Sociology, No. 3.

Koenig, H. G. (2007). Spirituality and Depression: A Look at the Evidence. Southern Medical Journal, 100, 737-739. http://dx.doi.org/10.1097/SMJ.0b013e318073c68c

Lawler-Row, K. A. Karremans, C., \& Scott, C. (2008). Forgiveness, Physiological Reactivity and Health: The Role of Anger. International Journal of Psychophysiology, 68, 51-58. http://dx.doi.org/10.1016/j.ijpsycho.2008.01.001

Lawler-Row, K. A., \& Piferi, R. L. (2006). The Forgiving Personality: Describing a Life Well Lived? Personality and Individual Difference, 41, 1009-1020. http://dx.doi.org/10.1016/j.paid.2006.04.007

Maclachan, A. (2012). Encyclopedia of Applied Ethics (2nd ed.). Toronto: York University Press.

Maddahi, M. I., Samadzadeh, M., \& Keikhai Farzaneh, M. M. (2011). The Study of the Relationship between Religious Orientation and Psychological Well-Being in Students. Journal of Educational Psychology, 1, 25-32.

Maltby, J., Day, L., \& Barber, L. (2004). Forgiveness and Mental Health Variables: Interpreting the Relationship Using an Adaptational-Continuum Model of Personality and Coping. Personality and Individual Differences, 37, $1629-1641$. http://dx.doi.org/10.1016/j.paid.2004.02.017

McCullough, K. I., Pargament, B., \& Thoresen, C. E. (2003). Forgiveness: Theory, Research, and Practice. New York: Guilford Press.

Mokhtari, A. (1990). The Investigation of the Relationship between Religious Orientation and the Components of the SelfConcept with the Rate of Stress in the Students of Tehran University and Tarbiat Modarres University. MA Thesis, Tehran: Tarbiat Modarres University.

Nori, T. I., \& Kazemi, N. (2012). The Study of the Relationship between Religious Orientation and Willingness to Forgiveness (Pardon) in Adolescents. 4th International Conference on Child and Adolescent Psychiatry, 20 May 2012, 243-245.

Rye, M., Loiacono, D., Folck, C., Olszewski, B., Heim, T., \& Madia, B. (2001). Evaluation of the Psychometric Properties of Two Forgiveness Scales. Journal of Current Psychology, 20, 260-277. http://dx.doi.org/10.1007/s12144-001-1011-6

Ryff, C. D. (1989). Happiness Is Everything or Is It? Explorations on the Meaning of Psychological Wellbeing. Journal of Personality and Social Psychology, 57, 1069-1081. http://dx.doi.org/10.1037/0022-3514.57.6.1069

Ryff, C. D., Singer, B. H., \& Love, G. D. (2004). Positive Health: Connecting Well-Being with Biology. Philosophical Transactions of the Royal Society of London B, Biological Sciences, 359, 1383-1394. http://dx.doi.org/10.1098/rstb.2004.1521

Seif, S., Bahari, F., \& Khosravi, Z. (2006). Forgiveness Scale Extended to the Iranian Families. Peer Reviewed Quarterly Journal of Woman's Studies, 6, 97-112.

Shekari, O., Dastjerdi, R., Daneshvarpour, Z., Ghanaei, Z., Zeinabadi, H. R., \& Geravand, F. (2007). Gender Differences in the Scales of Psychological Well-Being in Birjand University Students in the Academic Year 2005-2006. Journal of Birjand University of Medical Sciences, No. 3.

Teresa, M. M., Vinsonneau, J., Neto, F., Gerard, M., \& Mullet, E. (2003). Forgiveness and Satisfaction with Life. Journal of Happiness Studies, 4, 323-335. http://dx.doi.org/10.1023/A:1026251630478

Tse, W. S., \& Yip, T. H. (2009). Relationship among Dispositional Forgiveness of Others, Interpersonal Adjustment and Psychological Well-Being: Implication for Interpersonal Theory of Depression. Personality and Individual Differences, 46, 365-368. http://dx.doi.org/10.1016/j.paid.2008.11.001

Wink, P., Dillon, M., \& Larsen, B. (2005). Religion as Moderator of the Depression-Health Connection: Findings from a 
Longitudinal Study. Research on Aging, 27, 197-210. http://dx.doi.org/10.1177/0164027504270483

Yang, K.-P., \& Mao, X.-Y. (2007). A Study of Nurses' Spiritual Intelligence: A Cross-Sectional Questionnaire Survey. International Journal of Nursing Studies, 44, 999-1010. http://dx.doi.org/10.1016/j.ijnurstu.2006.03.004

Zahed Babolan, A., Ghasempour, A., \& Hasanzade, S. H. (2011). The Role of Forgiveness and Psychological Hardiness in Prediction of Hope. Journal of Knowledge and Research in Applied Psychology, 12, 12-19. 